\title{
SIMULTANEOUS ADSORPTION OF $\mathrm{CD}^{2+}, \mathrm{NI}^{2+} \mathrm{AND} \mathrm{PB}^{2+}$ ON PEAT
}

\author{
Ülis L. Sõukand \\ Tartu Environmental Research Ltd., Estonia
}

Pille Kängsepp

University of Kalmar, Sweden

University of Tartu, Estonia

University of Lund, Sweden

Renata Sõukand

Museum of Tartu University History, Estonia

Toomas Tenno

University of Tartu, Estonia

\section{ABSTRACT}

The aim of the present work was to investigate if locally available untreated peat could be used as filter material for the removal of heavy metals from leachate. The aqueous solutions containing $\mathrm{Cd}^{2+}, \mathrm{Ni}^{2+}$ and $\mathrm{Pb}^{2+}$ ions in single-metal and multi-metal solutions were used to study the adsorption of metals on peat. The peat was obtained from Southern Estonia. The decomposition rate of the peat was H6-H7 on the von Post scale. In order to assess the adsorption mechanism, the amounts of $\mathrm{Ca}^{2+}$ and $\mathrm{Mg}^{2+}$ ions desorbed from untreated peat were measured and compared to the adsorption efficiency of $\mathrm{Cd}^{2+}$, $\mathrm{Ni}^{2+}$ and $\mathrm{Pb}^{2+}$ ions from solution on the peat. The desorption of other cations, such as $\mathrm{Al}^{3+}, \mathrm{K}^{+}, \mathrm{Na}^{+}, \mathrm{Fe}^{3+}, \mathrm{Zn}^{2+}$ etc. were negligible during all experiments. Adsorption batch isotherm studies were carried out by using 10 experimental series with the initial concentration of $10-300 \mathrm{mg} / \mathrm{l}$. The samples were analyzed by using the axial ICP-AES. Results of the single- as well as multi-metal adsorptions show that peat can be effectively used. Adsorption of metals on molar basis was found in the indicated order: $\mathrm{Pb}^{2+}>\mathrm{Cd}^{2+}$ $>\mathrm{Ni}^{2+}$. The removal of single metal ions from ternary-metal solution was less than its removal from single-metal solution. However, the total adsorption capacity of metals from multi-metal solution to peat increased. The Langmuir isotherm equation constants were calculated and isotherms were drawn by using the program of calculating hyperbole functions. Correlations for $\mathrm{Ni}^{2+}$ and $\mathrm{Cd}^{2+}$ with the Langmuir isotherm equation was found to be good, whereas for $\mathrm{Pb}^{2+}$ the plot (amount absorbed vs. the equilibrium aqueous concentration) was linear. 


\section{KALMAR ECO-TECH'03 \\ Bioremediation and Leachate Treatment \\ KALMAR, SWEDEN, November 25-27, 2003}

KEYWORDS: Heavy metals; adsorption, desorption, magnesium, calcium, inductively coupled plasma; peat, multi-elemental adsorption

\section{INTRODUCTION}

The composition of leachate from industrial landfills is quite complex, containing heavy metals and different types of organic pollutants. Conventional sewage treatment methods may not be suitable for leachate treatment. Difficulties in the co-treatment of leachate and municipal wastewater include problems whit optimizing the treatment process and utilizing the excess sludge. In Sweden, the importance of co-treatment has been reduced. Even though no evidence of significant negative effects on treatment efficiency has been found, the sludge from co-treatment plants is not attractive for farmers. In many cases landfills are located far away from the sewerage system; therefore co-treatment may result in high transportation or pumping costs and environmental risks. Therefore, an environmentally friendly and economical on-site treatment method should be implemented.

Peat is an attractive filter-medium, since it is a cheap and widely available natural material. During the last decades, the use of peat has been investigated in many laboratory, pilot, and full-scale studies [1,2]. It has been demonstrated that peat is capable of removing heavy metals from single-metal ion solutions [3-5], as well as from binary [6], tertiary [7] and four or even more metal solutions [8].

Since the composition of peat, wastewater and leachate is site specific, investigations of the suitability of peat as filter material should be conducted in each case. The sorption of a metal ion from single-metal deionised water solution on the adsorbent is presumably affected by hydrogen ions and by the anion used in stock solution. The sorption of a metal ion from multi-metal water solution on the adsorbent is dependent on $\mathrm{pH}$ and is affected by other metal ions and by anions in stock solutions. In order to understand the process of metal removal from multi-component industrial effluents, both the sorption of heavy metal from single- and multi-metal solutions should be studied.

The objective of the study was to investigate the adsorption of lead, cadmium and nickel from single- and multi-metal solution on the peat. Influence of each metal on the adsorption of other metals was investigated. The possible ion exchange with calcium and magnesium during the adsorption process of lead, nickel and cadmium were also studied. These investigations are important for understanding the mechanism behind the removal process of heavy metals from the multi-component landfill leachate by peat filters.

\section{MATERIALS AND METHODS}

Batch experiments were made with peat, obtained from the Lange bog, Southern Estonia. The decomposition rate of the peat was $\mathrm{H} 6-\mathrm{H} 7$ on the von Post scale. The peat contained $51 \%$ organic matter, $2.8 \%$ of $\mathrm{N}$ and $41 \mathrm{mg}$ of $\mathrm{P}$ per $\mathrm{kg}$. The initial concentration of metals in the peat is presented in Table 1. In many investigations [9-11], peat was pre- 
KALMAR ECO-TECH'03

Bioremediation and Leachate Treatment

KALMAR, SWEDEN, November 25-27, 2003

treated (e.g. dried, washed with distilled water or $1 \mathrm{M} \mathrm{HCl}$ solutions etc.). However, any pre-treatment of peat before its use as a filter medium in a full-scale treatment plant will be time consuming and increase the cost. Therefore, the peat used in the experiments was untreated.

Adsorption batch isotherm studies were carried out. The peat $(1 \mathrm{~g})$ was placed in a $250 \mathrm{ml}$ conical flask, and $100 \mathrm{ml}$ of metal-containing solution was added. The initial $\mathrm{pH}$ of solutions was 5.6 and was not adjusted during the experiment. The flasks were shaken at $110 \mathrm{rpm}$ for 24 hours at $25^{\circ} \mathrm{C}$. After shaking the samples were filtered through a $0.45 \mu \mathrm{m}$ Himifil polyamide $25-\mathrm{mm}$ membrane filter and metal concentration in the solution was determined by the Varian Liberty II axial, inductively coupled plasma, atomic emission spectrometer (ICP-AES).

Table 1. Initial concentration of metals in peat.

\begin{tabular}{ccc}
\hline Metal & $\mathrm{mg} / \mathrm{g}$ & $\mu \mathrm{mol} / \mathrm{g}$ \\
\hline Cadmium & $0.05 \cdot 10^{-3}$ & $0.44 \cdot 10^{-3}$ \\
\hline Nickel & $4.1 \cdot 10^{-3}$ & 0.070 \\
\hline Lead & $1.1 \cdot 10^{-3}$ & $5.3 \cdot 10^{-3}$ \\
\hline Calcium & 22 & 550 \\
\hline Iron & 1.8 & 32 \\
\hline Magnesium & 1.5 & 62 \\
\hline
\end{tabular}

The single-metal ion stock solutions for cadmium, nickel and lead were prepared by dissolving their corresponding nitrate or chloride salts, $\mathrm{Cd}\left(\mathrm{NO}_{3}\right)_{2} * 4 \mathrm{H}_{2} \mathrm{O}, \mathrm{Pb}\left(\mathrm{NO}_{3}\right)_{2}$, $\mathrm{NiCl}_{2} * 6 \mathrm{H}_{2} \mathrm{O}$ in ultra pure water. The concentration of the metal ion in stock solutions was $1 \mathrm{~g} / \mathrm{l}$. These stock solutions were used for the dilution and mixing of single- and multi-metal solutions. The solutions were prepared and experiments were set up according to a method developed by Sag et al. (2001) [12].

Adsorption batch isotherm studies were carried out by using 10 series of experiments (SE).

The selected initial concentration range of metal ion solution for each metal ion on the basis of weight is shown in Table 2, SE 1-3. In order to compare the adsorption capacities of different metals with different molar masses, concentrations by weight should be recalculated for $\mathrm{mol} / \mathrm{l}$. In single-element solutions the initial concentrations of metal ions $\left(\mathrm{Cd}^{2+}, \mathrm{Ni}^{2+}\right.$ and $\left.\mathrm{Pb}^{2+}\right)$ corresponds to $180-1800,170-3400$ and $50-1200 \mu \mathrm{mol} / \mathrm{l}$, respectively. 
KALMAR ECO-TECH'03

Bioremediation and Leachate Treatment

KALMAR, SWEDEN, November 25-27, 2003

Table 2. Initial concentrations of metal ions in series of experiments.

\begin{tabular}{llll}
\hline $\begin{array}{l}\text { Series of } \\
\text { experi- } \\
\text { ments }\end{array}$ & $\mathrm{C}_{\mathrm{Cd}}(\mathrm{mg} / \mathrm{l})$ & $\mathrm{C}_{\mathrm{Ni}}(\mathrm{mg} / \mathrm{l})$ & $\mathrm{C}_{\mathrm{Pb}},(\mathrm{mg} / \mathrm{l})$ \\
\hline SE 1 & $20 ; 40 ; 60 ; 80 ; 100 ; 200$ & - & - \\
\hline SE 2 & - & 10,$20 ; 40 ; 60 ; 80 ; 100 ; 200$ & - \\
\hline SE 3 & - & - & 10,$20 ; 40 ; 60 ; 80 ; 100 ; 250$ \\
\hline SE 4 & $20 ; 40 ; 60 ; 80 ; 100 ; 200$ & 20 & 20 \\
\hline SE 5 & $20 ; 40 ; 60 ; 80 ; 100 ; 200$ & 40 & 40 \\
\hline SE 6 & 20 & 20 & $20 ; 40 ; 60 ; 80 ; 100 ;$ \\
\hline SE 7 & 40 & 40 & $20 ; 40 ; 60 ; 80 ; 100 ;$ \\
\hline SE 8 & 20 & $20 ; 40 ; 60 ; 80 ; 100 ; 200$ & 20 \\
\hline SE 9 & 40 & $20 ; 40 ; 60 ; 80 ; 100 ; 200$ & 40 \\
\hline SE 10 & $20 ; 40 ; 60 ; 80 ; 100 ; 300$ & $20 ; 40 ; 60 ; 80 ; 100 ; 300$ & $20 ; 40 ; 60 ; 80 ; 100 ; 300$ \\
\hline
\end{tabular}

The multi-metal solutions were prepared as follows: the solutions of one metal were prepared in concentrations of $20,40,60,80,100$ and $200 \mathrm{mg} / \mathrm{l}$, whereas the concentration of other two metals was 20 or $40 \mathrm{mg} / \mathrm{l}$ (Table 2, SE 4-9). One series of experiments (Table 2, SE 10) consisted of six solutions with equal concentrations of metals $(20,40$, $60,80,100$ and $300 \mathrm{mg} / \mathrm{l})$. In this experiments the residual concentration of $\mathrm{Al}, \mathrm{Ba}$, $\mathrm{Ca}, \mathrm{Co}, \mathrm{Cr}, \mathrm{Cu}, \mathrm{Fe}, \mathrm{K}, \mathrm{Mg} \mathrm{Mn}, \mathrm{Na}, \mathrm{P}, \mathrm{Zn}$ was measured in order to define the concentration of desorbed cations and phosphate. All experiments were duplicated.

\section{RESULTS}

\subsection{Desorption of calcium and magnesium from peat}

Using the possibilities given by the ICP-AES method, the most important metals desorbed from the peat were determined in addition to the three metals investigated. The concentration of desorbed $\mathrm{P}, \mathrm{Al}, \mathrm{Co}, \mathrm{Cr}, \mathrm{Cu}$ and $\mathrm{Mn}$ was less than $0.02 \mathrm{mg} / \mathrm{l}$. Also, the desorption rate of $\mathrm{Fe}, \mathrm{Ba}, \mathrm{K}, \mathrm{Na}$ and $\mathrm{Zn}$ was low, staying within the concentration of $0.01-0.5 \mathrm{mg} / \mathrm{l}$. Increasing of the concentration by adding 3 metals lifted the concentration of the equilibrium state only 2 times ( 10 times for $\mathrm{Zn}$ ). 


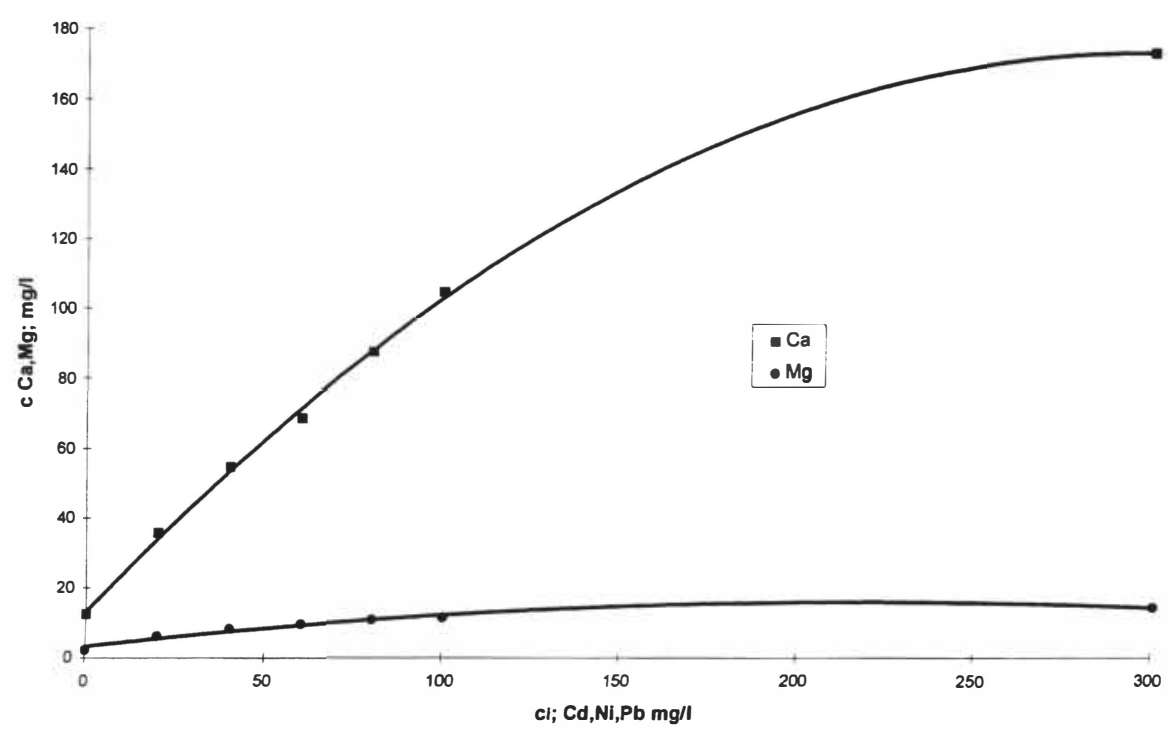

Figure 1. Desor ption of calcium and magnesium with multielement solutions at different initial concentrations.

The peat used for the investigations (see Table 1) contained mostly calcium, magnesium and iron, although the desorption of iron was poor $(0.03 \mathrm{mg} / \mathrm{l})$. The best desorption rate was found for calcium and magnesium - the concentration of desorbed ions in the equilibrium solution reached $170 \mathrm{mg} / \mathrm{l}$ and $15 \mathrm{mg} / \mathrm{l}$ correspondingly. In the monoelement solutions of nickel, cadmium and lead, the desorption of calcium and magnesium increased linearly at low concentrations, while at higher concentrations the plot became curved. The same trend was persistent in the case of multi-metal solutions (see Figure 1).

According to the molar concentration, the ratio of the desorption of calcium was equivalent to the adsorption of the three investigated metals. So it could be proposed that ion exchange is one of most important processes taking place on peat. The same conclusion was also reached by other researches, working on the adsorption properties of peat $[1,13]$.

\subsection{Adsorption of cadmium, lead and nickel from single-metal solutions}

To investigate the adsorption of $\mathrm{Cd}^{2+}, \mathrm{Ni}^{2+}$ and $\mathrm{Pb}^{2+}$ ions from single-metal solutions the solutions with 5 different adsorbate concentrations were used in the concentration range of 10-250 (see Table 2, SE 1-3). The results were used to build the isotherms showing a correspondence of adsorption ratio with the concentration of the metal in the solution in a state of equilibrium. The Langmuir isotherm equation constants were calculated and isotherms were drawn by using the program of calculating the hyperbole functions. 
KALMAR ECO-TECH'03

Bioremediation and Leachate Treatment

KALMAR, SWEDEN, November 25-27, 2003

Correlations for $\mathrm{Cd}^{2+}$ and $\mathrm{Ni}^{2+}$ with the Langmuir isotherm equation was found to be good, whereas for $\mathrm{Pb}^{2+}$ it was

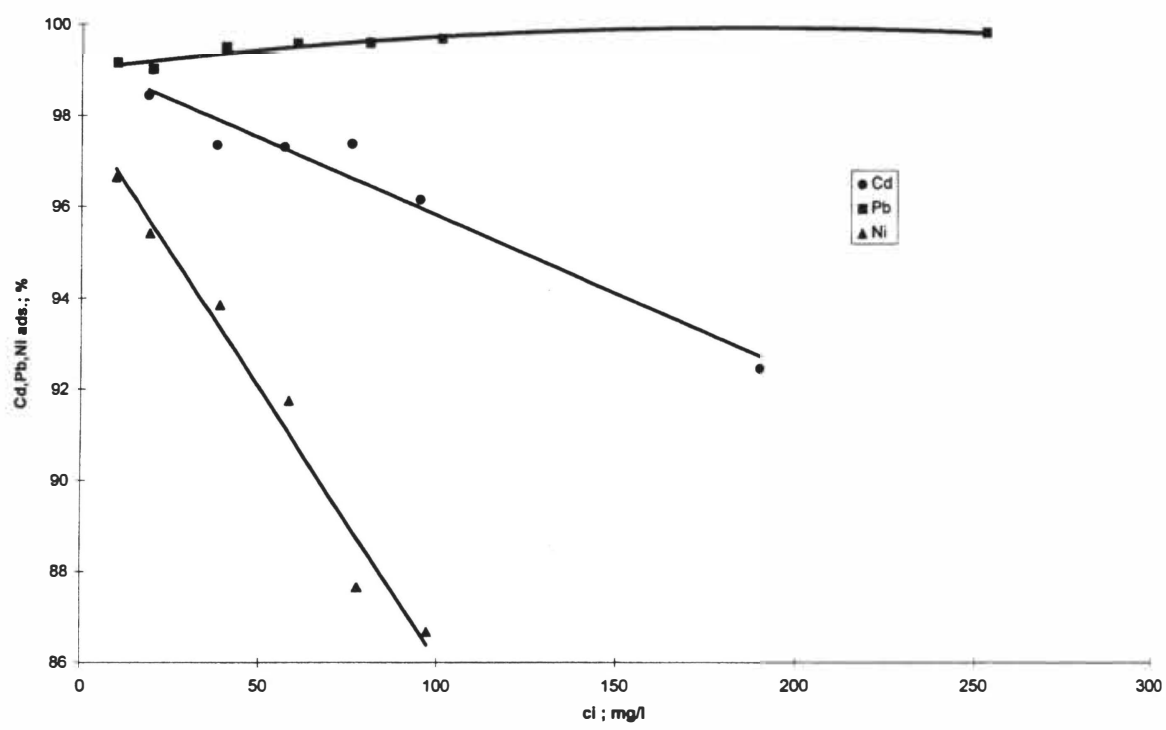

Figure 2. Dependence of adsorption $\%$ of $\mathrm{Cd}^{2+} \mathrm{e}, \mathrm{Ni}^{2+}$ and $\mathrm{Pb}^{2+}$ on the initial concentration of the solution.

poor. The correlation for lead in the investigated concentrations area was linear, which indicates that the adsorption of lead is much better than that of other metals.

Experiments showed that peat is a good sorbing material. The adsorption rate of lead was the highest $(99 \%$ in the studied concentrations area). The adsorption rate for cadmium was $\mathbf{9 2 - 9 8 \%}$ and for nickel $\mathbf{8 7 - 9 7 \%}$ in the investigated concentrations area. (see Figure 2). Adsorption of metals on molar and weight basis was found to be in the indicated order $-\mathrm{Pb}^{2}+>\mathrm{Cd}^{2+}>\mathrm{Ni}^{2+}$. This correlates with the data obtained by D'Avila (1992) [14] and Kapoor et al. (1999) [15].

\subsection{Co-adsorption of cadmium, lead and nickel}

In the case of multi-metal adsorption, one should take into consideration the role of other metals in the adsorption process. As was concluded during the investigation, $\mathrm{Ca}^{2+}$ and $\mathrm{Mg}^{2+}$ were substituted for by $\mathrm{Cd}^{2+}, \mathrm{Ni}^{2+}$ and $\mathrm{Pb}^{2+}$ relatively equally and that means that in the case of multi-metal solution they should compete for the same adsorption centres. In 
KALMAR ECO-TECH'03

Bioremediation and Leachate Treatment

KALMAR, SWEDEN, November 25-27, 2003

the case of lower concentration, there is literally no reciprocal influence of metals, but by the increasing of the initial concentration the level of saturation for adsorption centres seems to be reached and the influence of the presence of other metals is substantial (see Figure 3). It works for the adsorption of cadmium and nickel. For lead the tendency is different namely the addition of other metals increases the adsorption of lead at lower concentrations.

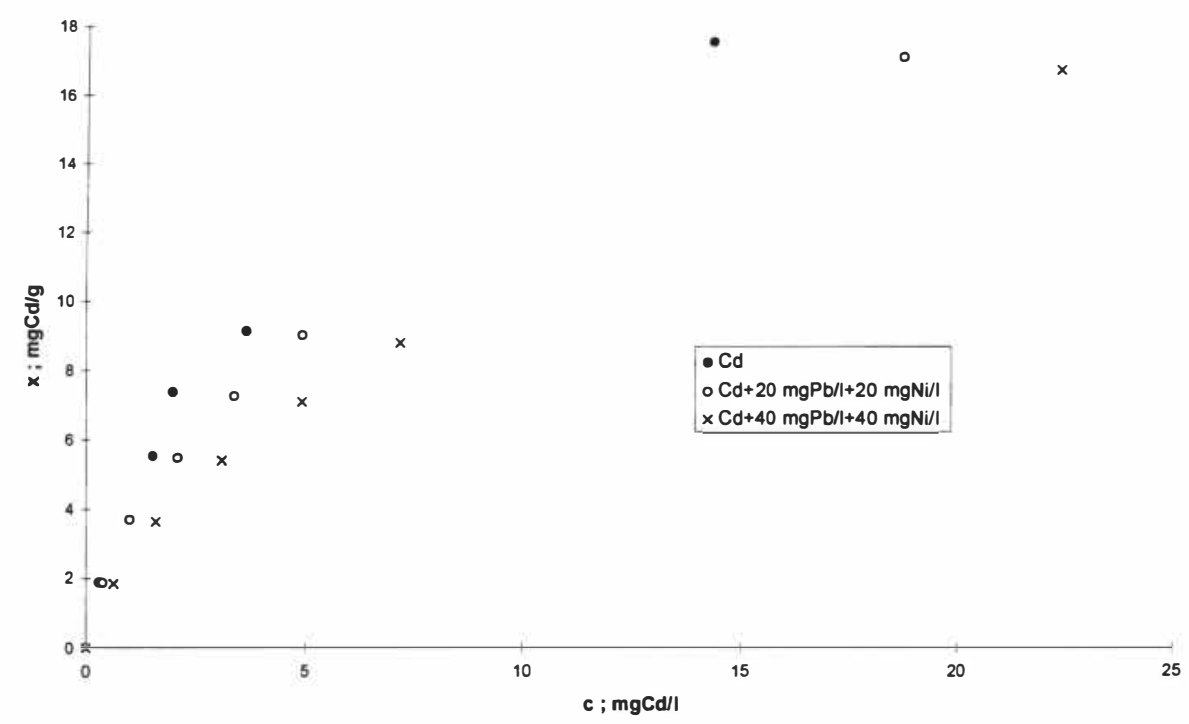

Figure 3. Influence of adding of other metals on the adsorption of cadmium.

\section{CONCLUSIONS}

As concluded, locally-available peat can be utilized as filter material, providing low cost and simple technology for the removal of metals. These investigations show that:

- desorption of other cations except $\mathrm{Ca}^{2+} \mathrm{ja} \mathrm{Mg}^{2+}$ from natural peat was negligible during all experiments

- ions of calcium and magnesium are replaced by ions of heavy metals - ion exchange could be one of the most important processes taking place during adsorption

- adsorption of metals on molar as well as weight basis was found in the indicated order: $\mathrm{Pb}^{2+}>\mathrm{Cd}^{2+}>\mathrm{Ni}^{2+}$. The sorption rate for lead was the best $(99 \%)$, for other metals it was $87-98 \%$ 
KALMAR ECO-TECH'03

Bioremediation and Leachate Treatment

KALMAR, SWEDEN, November 25-27, 2003

- the removal of single metal ions from ternary-metal solution was less than its removal from single-metal solution. However, the total adsorption capacity of metals from ternary solution to peat increased.

Moreover, these studies contribute to a better understanding of the mechanism of the removal of heavy metals from water solution on peat. Laboratory tests provide information for the planning of a full-scale filter-bed leachate treatment system.

\section{ACKNOWLEDGEMENTS}

The authors wish to thank Tartu Environmental Research Ltd. for the laboratory equipment, chemicals and working space provided.

\section{REFERENCES}

[1] Brown, P. A., Gill, S. A., Allen, S. J., 2000. Metal removal from wastewater using peat. Wat. Res. 34(16), 3907-3916.

DO1: https://doi.org/10.1016/S0043-1354(00)00152-4

[2] Couillard, D., 1994. The use of peat in wastewater treatment. Water Research 28, 1261-1274 DO1: https://doi.org/10.1016/0043-1354(94)90291-7

[3] Sõukand, Ü., Tungel, R., Tenno, T., 1996. Comparison of heavy metal adsorption properties on natural and granulated peat on the example of cadmium. Proceedings of the Estonian Acad. Sci. Chem. 45(3-4), 123-129.

[4] Sõukand, Ü., Sõukand, R., Maširin, A., Tenno, T., 2002. The Langmuir two-surface equation for cadmium adsorption on peat. A new method of the calculation of equation constants. Environ Sci \& Pollut Res. Special Issue 1. First Baltic Symposium, 43-48.

[5] Dissanayake, C. B., Weerasooriya, S. V. R., 1981. Peat as a Metal-Trapping Material in the Purification of Industrial Effluents, Research report. Intern. J. Environmental Studies 17, 233-238. DOl: https://doi.org/10.1080/00207238108709912

[6] Viraraghavan, T., Rao, G. A. K.,1992. Adsorption of cadmium and chromium from wastewater by peat. In: Proceedings of the $47^{\text {th }}$ Purdue Industrial Waste Conference, Lewis Publishers, Inc., Chelsea, Michigan,USA, 678-688.

[7] Viraraghavan, T., Dronamraju, M. M.,1993. Removal of copper, nickel and zinc from wastewater by adsorption using peat. J. Environ. Sci. Health A28(6), 1261-1276.

DO1: https://doi.org/10.1080/10934529309375941

[8] Aldrich, C., Feng, D., 2000. Removal of heavy metals from wastewater effluents by biosorptive flotation. Minerals engineering 13(10-11), 1129-1138.

DO1: https://doi.org/10.1016/S0892-6875(00)00096-0

[9] Ong, H. L., Swenson, V. E., 1966. Adsorption of copper by peat, lignite and bituminous coal. Econ. Geol. 61, 1214-1231

DO1: https://doi.org/10.2113/gsecongeo.61.7.1214 
KALMAR ECO-TECH'03

Bioremediation and Leachate Treatment

KALMAR, SWEDEN, November 25-27, 2003

[10] Chistova, L. R., Rogach, L. M., Sokolova D.V., Pekhtereva V.S., 1990. Removal of heavy metal ions from electroplating wastewaters by granulated peat (rus). Torf Prom-st $2,25-28$

[1 1] Gosset, T., Trancart J-L., Thevenot D. R., 1986. Batch metal removal by peat. Kinetics and thermodynamics. Wat. Res. 20(1), 21-26

[12] Sag, Y., Akcael B., Kutsal T., 2001. Evaluation, interpretation, and representation of three-metal biosorption equilibria using a fungal biosorbent, Process Biochemistry 37, $35-50$

[13] Mcnevin, D., Barford, J. 2001. Inter-relationship between adsorption and $\mathrm{pH}$ in peat biofilters in the context of a cation-exchange mechanism. Wat. Res. 35 (3), 736-744.

[14] D'Avila, J.S., Matos, C.M., Cavalcanti, M.R., 1992. Heavy metals removal from wastewater by using activated peat. Wat Sci Tech 26, 2309-2312

[15] Kapoor, A., Viraraghavan, T., Cullimore, D. R., 1999. Removal of heavy metals using the fungus Aspergillus niger. Bioresource Technology 70, 95-104. 